\title{
Integrated structures and materials design
}

\author{
Victor C. Li
}

Received: 31 May 2005/ Accepted: 2 January 2006

(C) RILEM 2006

\begin{abstract}
This paper introduces the concept of Integrated Structures and Materials Design (ISMD). ISMD combines materials engineering and structural engineering for the purpose of more effectively achieving targeted structural performance, by adopting material composite properties as the shared link. An application example, design of a bridge deck link-slab, is used to illustrate the essential elements of ISMD. It is shown that the composite hardened properties-tensile strain capacity, microcrack width, and Young's Modulus, as well as composite self-consolidating fresh properties, are amongst the most important composite parameters that govern the targeted structural performance of safety, durability and ease of design and implementation. These are also properties that can be controlled in an Engineered Cementitious Composite-an ultra ductile concrete, by tailoring the ingredients for desired fiber, matrix and interface micromechanical parameters. Broad implications of ISMD on educational approach, research collaboration, and next generation infrastructure development, are briefly discussed.
\end{abstract}

\footnotetext{
V. C. Li $(\bowtie)$

Department of Civil and Environmental Engineering, Department of Materials Science and Engineering, University of Michigan, Ann Arbor, MI 48109-2125, USA

e-mail: vcli@umich.edu
}

Keywords Composite $\cdot$ Micromechanics $\cdot$ ISMD · ECC $\cdot$ Bridge link-slab

\section{Introduction}

In recent years, structural design codes in many countries have moved or are moving towards performance based design concepts (see, e.g. [1]) in place of the classical prescriptive approach. The performance based design concept allows for greater flexibility, e.g., in dimensioning and reinforcement detailing by structural engineers. It also allows for a larger degree of freedom in construction material choice. To fully exploit this last aspect, it is desirable to have a larger repertoire of concrete materials, particularly those with properties drastically improved over the limitations of current concrete. Performance based design creates opportunities for collaboration between structural engineers and materials engineers.

In the last 10 years, systematic engineering of ultra high ductility concrete containing short discontinuous fibers has proceeded at a rapid pace, to the point where such materials have been placed in full-scale structures (see, e.g. [2]). Worthy of note is that these materials and their tensile properties are deployed for enhancing structural functions. These include, for example, an ultra ductile concrete used in a superthin composite steel/concrete bridge deck in 
Hokkaido, Japan, and in coupling beams for a tall building in central Tokyo in Japan. The successful development and application of such material relies heavily on the micromechanics based approach adopted in the material design process.

These two development trends, performance based structural design and the micromechanics based concrete material design, offer an interesting window of opportunity for structural engineers and material engineers to integrate their knowledge in order to attain structural performance not feasible heretofore. This integrated approach remains largely unexplored, partly because both trends are relatively recent, but also partly due to the cultural gap between the structural engineering and materials engineering communities. Bridging the gap between these two communities can bring significant enrichment to the fields of structural engineering and materials engineering, and further the innovative development of both.

The primary objective of this paper is to present the concept of the integrated structural and materials design (ISMD) as a collaborative research platform. ISMD acknowledges material (macroscopic or composite) properties as the common link between structural engineering and materials engineering, and that these material properties are "designable" by suitable microstructure tailoring. In the following, the concept of ISMD is described. An example of a bridge deck link-slab is used to illustrate this concept. Elements of micromechanics tools employed in the ductile concrete design are highlighted. Finally, a discussion on the implications of ISMD on future research directions is given.

\section{The concept of integrated structures and materials design}

In the world of structural engineering, materials are shaped into structural elements that are then assembled into structural systems in order to meet targeted structural functions and performance goals. The performance goals are often stated in terms of ultimate limit states or serviceability limit states. Typically, design codes provide the structural design framework with respect to material selection, dimensioning, and in the case of reinforced concrete, reinforcement detailing. Embodied within design codes are deep knowledge developed from structural mechanics analyses and verified by extensive experimental investigations and experience. Structural analyses utilize mechanical properties of materials in the form of constitutive laws. Thus structural mechanics forms the basic analytic tool for structural engineers. This body of knowledge while not visible to the eye, is the fundamental reason why structures (in most instances) carry anticipated loads in a predictable way. The world of structural engineering, shaping materials into structural elements and joining them to form structural systems, with structural performance as the target, is depicted as the upper triangle in Fig. 1.

In the world of materials engineering, raw ingredients are shaped into a composite through processing. Traditionally, raw ingredient selection is based on empiricism. In recent years, as knowledge of the impact the various phases in a composite have upon macroscopic properties increases, composite materials with specific desirable properties have been systematically designed. A particularly useful set of analytic tools for fiber reinforced cementitious composite design is micromechanics, which quantifies the mechanical interaction between fiber, matrix and fiber/matrix interface and relates this interaction to composite material properties. Micromechanics in this form can be considered analogous to structural mechanics where the fiber, matrix and

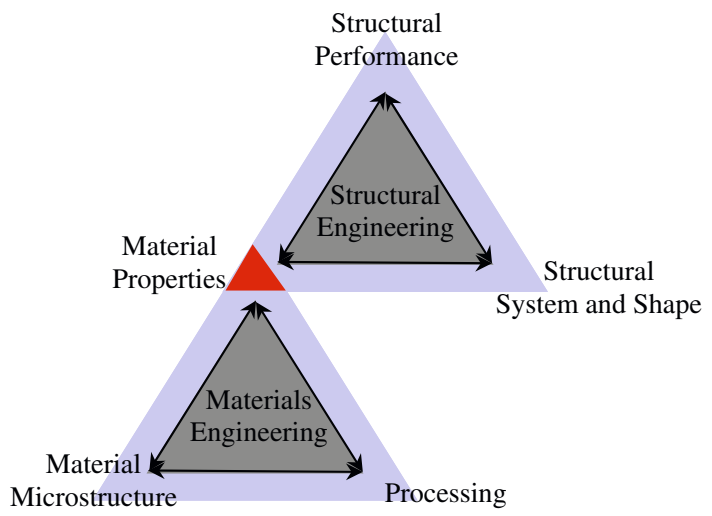

Fig. 1 Integrated structures and materials design-a collaborative platform for structural engineering and materials engineering 
interface serve as loading-carrying 'members', and the composite is regarded as the structural system. Naturally, the length scales are much smaller, and some mechanical or physical phenomena are unique to composite materials. Micromechanics can be a powerful tool to deliberately tailor the composite ingredients, such as fiber dimensions and surface coatings, along with sand particle amount and size. In addition, knowledge of material processing and its effect on both fresh and hardened properties aids in composite design. Again, while not visible to the eye, this body of knowledge on micromechanics and processing allows systematic development of composites with properties not reachable heretofore. The world of materials engineering, with composite property as the target, is depicted as the lower triangle in Fig. 1.

It is clear from the above discussion and from Fig. 1 that the common link between structural engineering and materials engineering is composite properties. As pointed out previously, performance based design of structures provides flexibility and incentive to deliberately select composite materials with properties that efficiently meet the structural performance target. In turn, modern materials engineering provides the tools for intentionally tailoring material ingredients for desired composite properties. Thus, the integration of structural and materials design is a natural joining of these technical fields. In other engineering fields such as aerospace engineering, such integration has already been in practice for some time. In the discipline of civil engineering, this tighter integration can bring about innovative structural systems unattainable if chasms between the structural engineering and materials engineering fields remain.

In most universities, structural engineering and materials engineering are two sub-disciplines within civil engineering. Students in one sub-discipline may lack exposure to the other sub-discipline in their education. This trend unfortunately perpetuates the separation of the two fields as these students continue on as practicing structural or construction materials engineers. In this light, ISMD is not only a collaborative research platform, but also serves as an integrated education platform for future generations of engineers.
Although the concept of integrated structures and materials design is appealing, its implementation faces obstacles requiring attention from both the structural engineering and the materials engineering communities. A shift in mind-frame is needed. The list below is not intended to be exhaustive, but is considered fundamental:

- Material properties characterization should be carried out in such a way that the resulting information can be captured as parameters in constitutive models usable in structural analyses. While this may appear obvious, current standard material tests such as ASTM C1018 which measures toughness based on flexural beams, are of limited use for structural design. It is known that such test results depend on beam height, and are meant to serve only as indices for comparing the relative energy absorption of different fiber mixes.

- Structural performance should be translated into demands on composite material properties, and not on specific fiber types. This recognizes that it is the composite properties that govern the structural performance, and not the fiber type. It is understood that fiber type plays an important role in composite properties, but fiber type is only one of many ingredient parameters that govern composite properties. In other words, a specific fiber may give better or worse composite property depending on the interface characteristics and matrix composition.

- For ISMD to be successful, materials engineers need to view structural performance as the ultimate goal if materials engineering is to maximize its potential impact on the future practice of civil engineering. Structural engineers need to recognize that increasingly, (beyond dimensioning, and reinforcement type and detailing) concrete materials properties are readily designable, and that in many instances the global performance of a structure can be strongly governed by properties other than compressive strength of concrete materials.

Along these lines, the upper triangle in Fig. 1 needs to embrace the lower triangle as an additional degree of freedom of structural design 
(beyond dimensioning, reinforcement detailing, and choice of concrete compressive strength), while the lower triangle needs to reach upward and embrace structural performance as the ultimate material design objective. These expanded mind-frames support meaningful interactions and collaboration between the two allied communities necessary for the common good of next-generation infrastructure systems which are safe, durable, and sustainable.

\section{Illustration of the use of ISMD}

In this section, the use of ISMD is illustrated by using the structural design of a bridge deck linkslab as an example. This example is chosen because of its relative design simplicity, as well as the fact that it fully exploits ISMD. Another illustration of ISMD using a self-centering seismic moment frame can be found in [3]. ISMD typically involves three main steps: (a) translation of targeted structural performance to desired material properties, (b) design of composite material to meet the desired material properties, and (c) design of the structure based on actual attainable composite properties. These three steps for the link-slab design are detailed below.

\subsection{Translation of targeted structural performance to desired material properties}

Conventional expansion joints of concrete bridge decks are needed to accommodate deck movements due to live load, temperature variations, and material shrinkage. Without expansion joints, random cracking and crushing of the deck would result from such mechanical and environmental loading. Unfortunately expansion joints often jam, resulting in leakage of aggressive agents through the deck, causing damage on beam-ends, and requiring expensive and frequent joint maintenance. One proposed solution to this problem is the use of reinforced link-slabs. Linkslabs are designed to replace the expansion joint and surrounding concrete while still accommodating movements of the adjacent spans so that the deck becomes continuous. The link-slabs, partially debonded from the girder, then serve as hinges over the simply supported beams and connected to the adjacent concrete slabs via steel reinforcements. A shortcoming of concrete link slabs is that they require heavy steel reinforcement to control the crack width in order to maintain durability. Success in crack control is sensitive to the correct design and placement of this steel reinforcement. Large steel reinforcement ratios result in stiffening of the link-slab, contrary to the desire of a flexible hinge.

Thus the performance target of a concrete linkslab can be summarized as:

- Adequate moment capacity to resist bending load caused by rotation of the adjacent slabs due to expected maximum live loads

- Maintain durability by controlling crack widths in the slab in the presence of deck movement due to temperature variations, live load and material shrinkage

- Maintain hinge action to comply as much as possible with the original simple span design.

The first and second performance targets suggest high steel reinforcement ratios, while the third target suggests a low ratio. These contradictory requirements can be resolved if the crack width in the concrete can be self-controlled. This essentially decouples the need for crack width control from steel reinforcement required for moment capacity assurance. Indeed, as the link slab becomes more flexible with lower steel reinforcement ratios, the section stiffness and therefore the moment induced actually decreases so that the first performance target can also be met more easily. It is of course well known that normal concrete or even normal fiber reinforced concrete does not have the capability of selfcontrolled crack widths. Once cracked, concrete depends on steel reinforcement to control crack widths.

Assuming a link-slab of 5\% the length of each adjacent deck slab as suggested by Caner and Zia [4], the imposed tensile strain related to imposed deformation by temperature, live load and shrinkage is calculated to be around $1.6 \%$, adopting a factor of safety of two [5]. This implies that cracking in concrete link-slabs is inevitable since normal concrete has a tensile strain capacity of $0.01 \%$. Furthermore, cyclic fatigue loading due 
to traffic movements may be expected to widen the width of concrete cracks over time [6].

According to previous ACI [7] and AASHTO codes [8], crack widths should be kept below $330 \mu \mathrm{m}$ as outdoor exposure limit for durability. Based on water permeability test data (e.g. [9]), concrete cracks below $100 \mu \mathrm{m}$ have the same coefficient of permeability as sound concrete. This stringent requirement is desirable but difficult, if not impossible to achieve with normal concrete. Gilani and Jansson [10] reported that the eight concrete link-slabs built in Michigan between 2001 and 2003 generally perform well when carefully designed and constructed. In under-performing link slabs with inadequate amounts of reinforcement, crack widths of 250 $500 \mu \mathrm{m}$ were found.

A new type of ductile concrete material is needed to optimally meet the specified structural performance target. Ideally this ductile concrete should have the following characteristics:

- A tensile strain capacity exceeding $1.6 \%$, needed to meet all three structural performance targets with a minimum amount of steel reinforcement;

- Within this straining range, the material must not crack, or if it does crack, must have crack width self-controlled to below $100 \mu \mathrm{m}$;

- For the hinge action performance target, a low Young's modulus is preferred;

- The material should resist fatigue loading so that the crack widths, if any, should remain below $100 \mu \mathrm{m}$ during its service life; and

- To support traffic load acting on the linkslab, all other properties of normal concrete, including compressive strength (minimum of $35 \mathrm{MPa}$ at 28 days), should be maintained.

This specification of the ideal material properties completes the translation of desired structural performance to desired material properties as represented in the upper triangle in ISMD (Fig. 1). From hereon, this set of desired material properties becomes the target of composite material design by the materials engineer. Their responsibility is to tailor material ingredients so that the resulting composite can meet the above set of material characteristics, and be processed under field conditions typical of bridge deck construction or retrofit, as represented by the lower triangle in ISMD. For practical reasons, the material should be producible by regular construction equipment found in the field for current practices.

\subsection{Design of composite material to meet the desired material properties}

To maintain physical and mechanical compatibility between the link-slab and the deck-slab, it is desired to use a Portland cement based composite for the link-slab. The high tensile strain capacity demand cannot be met by tension-softening fiber reinforced concrete. Although some continuous fiber reinforced mortar and cement composites with high fiber content may meet this demand, their difficult fabrication process prevent them from direct casting in the field for the purpose of bridge deck retrofitting. The high cost associated with high fiber content will make the material economically infeasible for field adoption. One possibility is to use an Engineered Cementitious Composite (ECC) [11] designed with $2 \%$ by volume of short, discontinuous PVA REC-15 fiber. This composite material can self-consolidate, making it very easy to cast. The mix composition detailed in Table 1, have been determined by applying micromechanics principles. For details of micromechanics theory behind this design, the reader is referred to $\mathrm{Li}$ and co-workers $[12,13]$.

As can be seen, ECC is made with many of the same ingredients found in normal concrete, less the coarse aggregates. The mortar containing fine silica sand (maximum grain size $250 \mu \mathrm{m}$; average size $110 \mu \mathrm{m}$ ) has a deliberately low fracture toughness to allow microcracks to grow out from $\mathrm{mm}$-size initial defects such as air-voids when overloaded in tension. These microcracks are then immediately bridged by specially engineered fibers to control the opening of the crack, resulting in what is known as steady state propagation of flat cracks [14]. The width of these flat cracks can be limited to less than $100 \mu \mathrm{m}$ by 'proper' fiber bridging behavior [15], via control of fiber and interface properties. Typically, fibers with small diameter, high stiffness and strength, and strong interfacial bond to the mortar, provide the best possibility of limiting the flat crack width. 
Table 1 Mix proportion of PVA-ECC (Mix M45)

\begin{tabular}{ll}
\hline Component & Proportion \\
\hline Cement & 1.0 \\
Fly ash & 1.2 \\
Sand & 0.8 \\
Water & 0.58 \\
Superplasticizer & 0.013 \\
Fiber (vol\%) & 0.02 \\
\hline
\end{tabular}

However, excessive interfacial bond leads to fiber breakage instead of debonding and slip, returning the composite to a tension-softening FRC. When steady state flat crack propagation prevails, and if a suitable amount and size of initial defects are available in the mortar matrix, multiple cracking and an overall ductile response of the composite result. Thus, it is clear that amongst other requirements, successful design of ECC requires a matrix with limited toughness and an appropriate flaw system, strong and stiff fibers, and suitable interface bonding. In this way, micromechanics theory allows for a systematic and holistic approach to quantitatively tailor the material ingredients. For example, tailoring of a $40 \mu \mathrm{m}$ diameter and $12 \mathrm{~mm}$ long PVA fiber (overall Young's modulus $28.5 \mathrm{GPa}$ ) with a hydrophobic surface coating led to significant improvement in composite ductility [16]. The selection of matrix grain size and incorporation of Class $\mathrm{F}$ flyash in ECC also aids in achieving desirable rheological control of fresh properties for self-consolidating casting, while simultaneously limiting the matrix toughness to an appropriate level.

It is expected that trade-offs between composite tensile strength and tensile ductility are needed. For example, higher composite strength may be reached by engineering the mortar matrix to have a higher toughness and/or smaller initial flaws, at the expense of ductility. The optimal mix of strength and ductility depends on the particular structural application. For the link-slab, it is clear that tensile ductility is more important to sustain the large imposed deformation, and is given priority over strength. The mix composition of the ECC described in Table 1 provides all the necessary properties required of the link-slab application [11]. In particular, the tensile strength $\sigma_{\text {ty }}$ of $3.5 \mathrm{MPa}$, a yield strain $\varepsilon_{\text {ty }}$ of $0.02 \%$ (corresponding to a Young's modulus $E$ of $17.5 \mathrm{GPa}$ ), with a tensile ductility $\varepsilon_{\mathrm{tu}}$ of $2 \%$ (minimum), and a steady state crack width $w_{\mathrm{ss}}$ of $60 \mu \mathrm{m}$, meet the target composite property requirements specified above. A typical stressstrain curve of this material is given in Fig. 2. These material properties have been obtained from a uniaxial tension test [13]. The 28-day compressive strength $f_{\mathrm{c}}^{\prime}$ and strain capacity $\varepsilon_{\mathrm{c}}$ of this mix is about $75 \mathrm{MPa}$ and $0.43 \%$.

To ensure that this ECC will meet the serviceability requirements of the link-slab which will be constructed in Michigan with severe winter conditions, standard freeze-thaw durability tests were conducted. These tests [17] confirm that ECC behaves equivalent to air-entrained concrete, even without deliberate air-entrainment. Additional tests include wear tests conducted by MDOT [17] which verified the suitability of this material to be used on bridge decks subjected to heavy traffic volumes. A comparative study of PVA-ECC versus polymer cement mortar subjected to high cycle fatigue loading also indicates the superiority of the fatigue resistance of ECC [18].

\subsection{Design of the ECC-link-slab}

The design procedure of an ECC link-slab is detailed in Lepech and $\mathrm{Li}$ [19]. Experimental verification of the performance of ECC link-slab in accordance with this design is described in [5]. Here, a synopsis of the design aspects relevant to the present ISMD illustration is given.

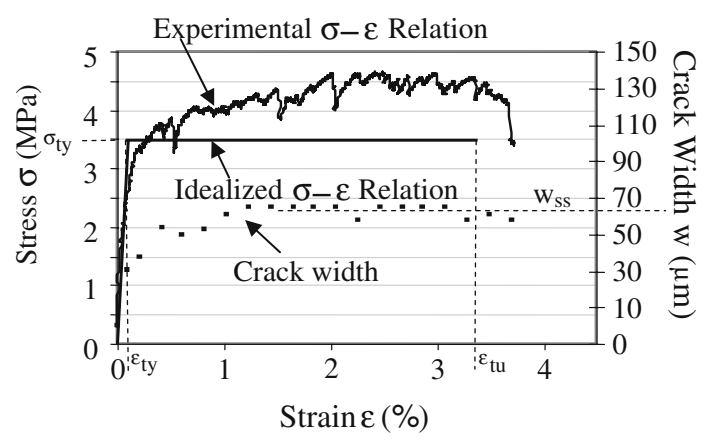

Fig. 2 A typical stress-strain and crack width development curve of ECC for link-slab application 
Fig. 3 Schematic of ECC link slab

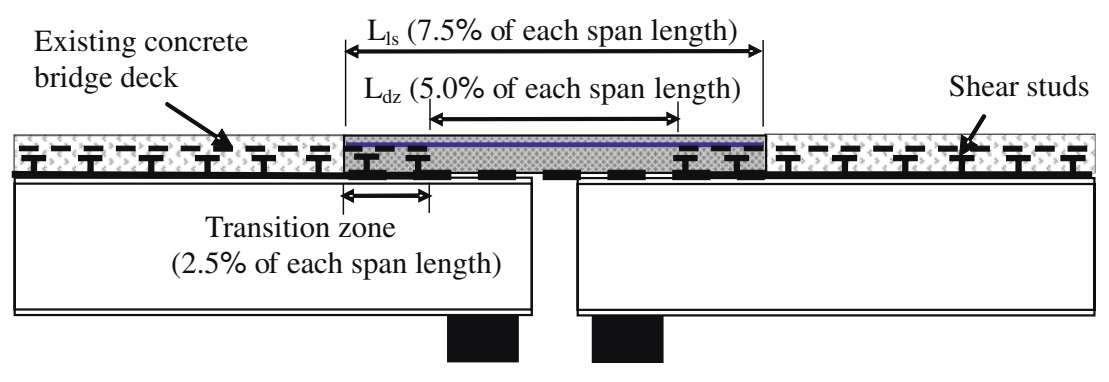

The geometry of the link-slab and its connection to the deck slabs and the supporting girder is shown in Fig. 3. The height of the length slab $t_{\mathrm{s}}$ is assumed the same as that of the adjacent concrete deck. The debond zone is the center section of the link slab in which all shear connectors between the girder and deck are removed to prevent composite action between girder and deck, so as to allow hinge action. Zia et al. [20] found that up to $5 \%$ of each adjacent bridge deck may be debonded without affecting the simple span design assumption of the adjacent spans. The full length $L_{\mathrm{ls}}$ of the link slab includes portions connected to the girders via shear studs. This geometry moves the high stress concentration at the ends of the debond zone away from the potentially weaker interfaces between the link-slab and the deck slabs.

The moment induced $M_{\mathrm{ls}}$ must be met by the moment capacity $M_{\mathrm{r}-\mathrm{ls}}$ of the link slab. $M_{\mathrm{ls}}$ can be obtained from the maximum (specified as allowable by different DOTs) end rotation $\theta_{\max }$ of the adjacent bridge spans, as

$M_{\mathrm{ls}}=\frac{2 E_{\mathrm{ECC}} I_{\mathrm{ls}}}{L_{\mathrm{dz}}} \theta_{\max }$

where $E_{\mathrm{ECC}}$ is the elastic modulus of ECC material and $I_{1 \mathrm{~s}}$ is the uncracked moment of inertia of the link slab. $M_{\mathrm{r}-\mathrm{ls}}$ can be obtained from a non-linear section analysis of the link-slab. Figure 4 shows the $\mathrm{X}$-section geometry, the typically assumed linear strain profile under bending load, and the corresponding stress profile in the section under negative moment. The linear elastic-perfectly plastic idealized tensile stressstrain curve shown in Fig. 2 is adopted. Following [4], it is further assumed that the stress in the reinforcement is limited to $40 \%$ of steel yield strength, $f_{\mathrm{y} \text {-steel }}$. This working stress design approach was originally intended to control concrete crack width, but becomes extremely conservative for ECC link-slab design as the ECC self-controls its crack width. Note that unlike concrete, ECC is allowed to carry tension equal to its "yield strength" $\sigma_{\text {ty }}$, as long as the tensile strain $\varepsilon_{\mathrm{T}}$ (at the outer-most fiber) does not exceed the tensile strain capacity $\varepsilon_{\mathrm{tu}}$. The stress profile description is completed by specifying the yield strain $\varepsilon_{\text {ty }}$ of ECC to be $0.02 \%$, as shown in Fig. 2.

The location of the neutral axis (represented by the unknown variable $d$ measured from the reinforcement to the N.A. in Fig. 4) can be determined by enforcing force equilibrium in the section. Subsequently, $M_{\mathrm{r}-\mathrm{ls}}$ can be obtained by summing moments about the neutral axis, as
Fig. 4 Stress and strain distributions in ECC link slab cross-section

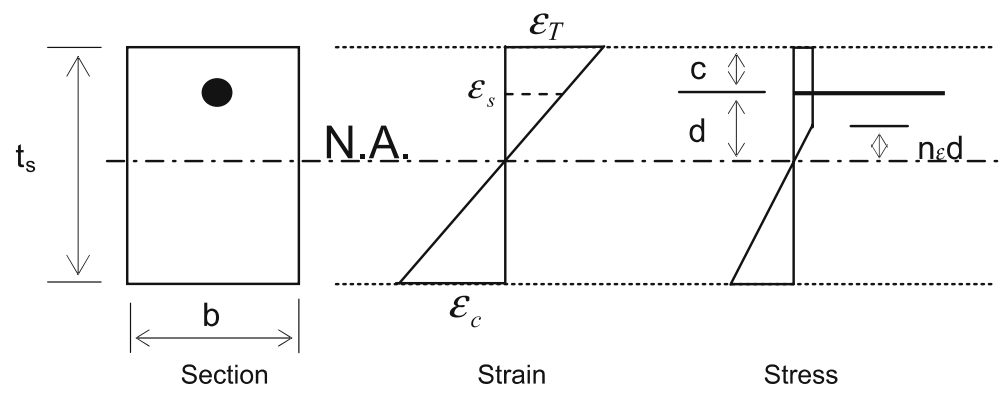




$$
\begin{aligned}
M_{\mathrm{r}-\mathrm{ls}}= & T_{\text {Steel }} \times d+T_{\mathrm{ECC}-2}\left(\frac{\left(1-n_{\varepsilon}\right) d+c}{2}+n_{\varepsilon} \times d\right) \\
& +T_{\mathrm{ECC}-1}\left(\frac{2}{3}\right) n_{\varepsilon} d+C_{\mathrm{ECC}}\left(\frac{2}{3}\right)(H-d-c)
\end{aligned}
$$

where

$n_{\varepsilon}=\frac{\varepsilon_{\mathrm{ty}}}{0.4 \varepsilon_{\mathrm{y}-\mathrm{steel}}}$

and

$$
\begin{aligned}
& T_{\text {steel }}=\left(0.4 f_{\mathrm{y}-\text { steel }}\right) \rho t_{\mathrm{s}} b \\
& T_{\mathrm{ECC}-2}=\sigma_{\mathrm{ty}}\left(\left(1-n_{\varepsilon}\right) d+c\right) b \\
& T_{\mathrm{ECC}-1}=\left(\frac{1}{2}\right) \sigma_{\mathrm{ty}} n_{\varepsilon} d b \\
& C_{\mathrm{ECC}}=\left(\frac{1}{2}\right) \sigma_{\mathrm{ty}}\left(\frac{1}{n_{\varepsilon}}\right)\left(\frac{1}{d}\right)\left(t_{\mathrm{s}}-d-c\right)^{2} b
\end{aligned}
$$

where $T_{\text {steel }}, T_{\mathrm{ECC}-1}, T_{\mathrm{ECC}-2}$, and $C_{\mathrm{ECC}}$ are the tensile force in the steel, the tensile force carried by ECC before and after "yield", and the compressive force carried by ECC in the compression zone, respectively.

By matching moment induced (1) to moment capacity (2), the amount of steel reinforcement $\rho$ needed can be determined.

The most important design check is to assure that the expected tensile and compressive strains are below those of the strain capacities of ECC material. The total tensile strain $\varepsilon_{t}$ is the sum of those induced by temperature $\varepsilon_{\mathrm{T}}$, by drying shrinkage $\varepsilon_{\mathrm{sh}}$ and by live load $\varepsilon_{\mathrm{LL}}$, i.e.

$\varepsilon_{\mathrm{t}}=\varepsilon_{\mathrm{T}}+\varepsilon_{\mathrm{sh}}+\varepsilon_{\mathrm{LL}}$

where

$$
\varepsilon_{\mathrm{T}}=\frac{\alpha_{\mathrm{T}} \times \Delta T \times \beta \times L_{\mathrm{long}}}{L_{\mathrm{dz}}}
$$

and

$\varepsilon_{\mathrm{LL}}=\frac{0.4 \times \varepsilon_{\mathrm{y} \text {-steel }} \times(d+c)}{d}$

where $L_{\text {long }}$ is the length of the longer adjacent span, and $\beta$ is a design value taken as 2.0 for joints with two roller bearings and 1.0 for all other joints. The compressive strain is given by

$\varepsilon_{\mathrm{c}}=\frac{0.4 \times \varepsilon_{\mathrm{y}-\text { steel }} \times\left(t_{\mathrm{s}}-d-c\right)}{d}$

The material check is then

$\varepsilon_{\mathrm{t}}<\varepsilon_{\mathrm{tu}} ; \quad \varepsilon_{\mathrm{c}}<\varepsilon_{\mathrm{cu}}$

If these checks are not met, then modifications of the link-slab geometry (particularly lengthening $L_{\mathrm{dz}}$ ) and/or the ECC material with higher strain-capacity will be needed. Additional design considerations and checks can be found in [19]. Unlike concrete link-slab design, it is not necessary to check crack width since as mentioned before, the crack width for ECC is self-controlled to below $100 \mu \mathrm{m}$.

With the selection of reinforcement ratio $\rho$, the moment capacity of the ECC link-slab is assured.

\section{Implications of ISMD}

It can be observed from the ECC link-slab example described that the application of ISMD requires the following: The structural engineer, in consultation with the owner of the structure, sets the agenda, in the form of specifying the structural performance target, and translating that target into a set of required composite material properties. The materials engineer conducts materials design based on this set of required composite material properties. In addition, all material characterization must be performed so that the material property data is usable in the structural design process.

ISMD, as represented by the two triangles overlapping at the corner of material properties, serves as a collaborative platform between the structural engineer and the material engineer. Material property is their common "language".

There are several broad implications of ISMD:

- ISMD encourages structural innovation via advanced materials development. It provides 
an additional degree of freedom for meeting structural performance targets through materials design, beyond structural element dimensioning, reinforcement detailing and choice of concrete compressive strength.

- ISMD encourages materials innovation with direct impacts on structural performance. It provides guidelines to proper material characterization, as well as incentives for developing tools for materials design.

- ISMD assists material suppliers to specify their material in a way meaningful to structural engineers. Robust material testing methods is also necessary.

- ISMD encourages students in structural and materials engineering to cross disciplinary boundaries so that they would be more effective in contributing to infrastructure development as future engineers.

- ISMD provides a meaningful platform of collaborative research between structural and materials researchers.

- ISMD supports the elevation of sustainability as a primary infrastructure design target, through integration of green material design and processing, and structural durability [21].

In civil engineering practice, day-to-day use of ISMD, at least in the current situation, is not yet practical. Greatly simplified methods of handshaking between structural engineers and materials engineers need to be developed. It is a major challenge to researchers to establish this handshaking methodology. In the future, structural engineers may be able to "dial up", or map desirable material properties to appropriate material mix designs using a networked computer database that has embedded materials design knowledge.

\section{Conclusions}

This article describes the concept of ISMD, driven by the increasing prevalence of performance based design of structures, and by the recent development of micromechanics based tools for materials engineering. The concept of ISMD is illustrated with the design of a bridge deck linkslab. A specially engineered ECC material is adopted to meet the ductility and durability demanded by the specified structural performance target. ISMD has wide ranging implications. While ISMD provides an excellent collaborative research platform between structural engineers and materials engineers, the practical adoption of ISMD in the civil engineering profession will require investigation into establishing simple "dial-up" tools. Such dial-up tools will add a new degree of freedom in the pursuit of performance based structural design.

Acknowledgments The authors thank the Michigan Department of Transportation and the National Science Foundation for funding this research (CMS-0223971, CMS-0329416, and CMS-0070035). Helpful discussions with S. Billington, M. Lepech, J. Lynch and H. Stang are acknowledged.

\section{References}

1. SEAOC (1995) Vision 2000: A framework for performance based engineering of buildings, Structural Engineers Association of California, Sacramento, CA

2. Li VC (2004) Strategies for high performance fiber reinforced cementitious composites development. In: Ahmad S, di Prisco M, Meyer C, Plizzari GA, Shah S (eds) Fiber reinforced concrete: from theory to practice, Proc. N. American/European Workshop on Advances in Fiber Reinforced Concrete, Bergamo, Italy, pp. 93-98

3. Li VC, Fischer G (2002) Reinforced ECC-an evolution from materials to structures. Proceedings of the First FIB Congress, Osaka, Japan, October 2002, pp. $105-122$

4. Caner A, Zia P (1998) Behavior and design of link slabs for jointless bridge decks. PCI Journal MayJune:68-80

5. Kim YY, Fischer G, Li VC (2004) Performance of bridge deck link slabs designed with ductile ECC. ACI Struct J 101(6):792-801

6. Matsui S (1997) Technology developments for bridge decks-innovations on durability and construction (in Japanese). Kyouryou To Kiso (8):84-92

7. American Concrete Institute (1995) Building code requirements for structural concrete (ACI 318-95) and commentary (ACI 318R-95). American Concrete Institute, Farmington Hills, MI

8. American Association of State Highway and Transportation Officials (1998) AASHTO LFRD Bridge design specifications: Second Edition. AASHTO. Washington, DC, USA, pp. 5-41

9. Wang K, Jansen D, Shah S, Karr A (1997) Permeability study of cracked concrete. Cement and Concrete Research 27(3):381-393

10. Gilani A, Jansson P (2004) Link slabs for simply supported bridges. MDOT Report Number MDOT SPR-54181, Structural Research Unit, Construction 
and Technology Support Area, Michigan Department of Transportation. Lansing, Michigan

11. Wang S, Li VC (2005) Polyvinyl alcohol fiber reinforced engineered cementitious composites: material design and performances. In: Proc., Int'l Workshop on HPFRCC Structural Applications, Hawaii, May 2005

12. Li VC (2003) On Engineered Cementitious Composites (ECC) - A Review of the Material and its Applications. J Adv Concrete Technol 1(3):215-230

13. Li VC, Wang S, Wu C (2001) Tensile strain-hardening behavior of PVA-ECC. ACI Mater J 98(6):483-492

14. Li VC, Leung CKY (1992) Steady state and multiple cracking of short random fiber composites. ASCE J Eng Mech 118(11):2246-2264

15. Wang S (2005) Micromechanics based matrix design for ECCs, PhD Thesis, University of Michigan, Ann Arbor, April, 2005

16. Li VC, Wu C, Wang S, Ogawa A, Saito T (2002) Interface tailoring for strain-hardening PVA-ECC. ACI Mater J 99(5):463-472

17. Li VC, Lepech M (2004) Crack resistant concrete material for transportation construction. In:
Transportation Research Board 83rd Annual Meeting, Washington, D.C., Compendium of Papers CD ROM, Paper 04-4680, 2004

18. Suthiwarapirak P, Matsumoto T, Kanda T (2002) Flexural Fatigue Failure Characteristics of an Engineered Cementitious Composite and Polymer Cement Mortars. J Materials Conc Struc Pavements JSCE 718(57):121-134

19. Lepech M, Li VC (2005) Design and field demonstration of ECC link slabs for jointless bridge decks. ConMat'05, Vancouver, Canada, August, 2005, CDdocuments/1-05/SS-GF-05_FP.pdf

20. Zia P, Caner A, El-Safte AK (1995) Jointless bridge decks, research project 23241-94-4. Center for Trans. Eng. Studies, North Carolina State, pp. 1-117

21. Keoleian GA, Kendall A, Dettling JE, Smith VM, Chandler R, Lepech MD, Li VC (2005) Life cycle modeling of concrete bridge design: comparison of engineered cementitious composite link slabs and conventional steel expansion joints. In: ASCE J Infrastruct Syst 51-60 